\title{
Comparing Three Distinct Samples on Traumatic Events, Post Traumatic Stress Disorder and Dysfunctional Coping Styles
}

\author{
Gary Blau ${ }^{1} \&$ Glen Miller ${ }^{1}$ \\ ${ }^{1}$ Fox School of Business and Management, Temple University, Philadelphia, USA \\ Correspondence: Gary Blau, HRM Department, Fox School of Business \& Management, Temple University, \\ Philadelphia, PA 19122. USA Tel: 1-215-204-6906
}

Received: November 8, 2020 Accepted: December 17, 2020 Online Published: January 4, 2021

doi:10.5539/jedp.v11n1p1

URL: http://doi.org/10.5539/jedp.v11n1p1

\begin{abstract}
The purpose of this study was to compare three distinct United States (US) samples on traumatic events, dysfunctional coping styles and Post Traumatic Stress Disorder (PTSD). The samples were: civilian $(n=97)$; non-combat military veterans $(n=61)$ and combat military veterans $(n=91)$. An online survey was used to collect all the data. The average age across all participants was 29 years old. For the overall combined sample, three avoidance coping styles, venting, denial, and dark humor, were each positively related to Post Traumatic Stress Disorder (PTSD). Looking at differences between the three samples, the combat veteran sample had more traumatic events (TEs), with the most recent TE being longer ago, then the non-combat veteran and civilian samples. There were no sample differences in PTSD. However, the non-combat veteran sample had higher levels of denial, venting and dark humor in dealing with their most recent TE, than the other two samples. This research draws needed attention to helping non-combat military veterans cope in a more positive way with their most recent TE. Future research directions and study limitations are discussed.
\end{abstract}

Keywords: avoidance coping styles, military veterans, post traumatic stress disorder, traumatic event

\section{Introduction}

\subsection{Importance of the Problem}

The 2019 United States (US) National Veteran Suicide Prevention Annual Report (Department of Veterans Affairs, 2019) found that military veteran suicides increased from 15.9 suicides per day in 2005 to 16.8 suicides per day in 2017. Issues related to both sobering statistics include understanding how well a military veteran transitions to civilian life (Weiss, Rubin \& Graeser, 2019). This transition can depend on such factors as: traumatic event(s) faced by a military veteran, post traumatic stress disorder (PTSD), and coping style in dealing with the most recent traumatic event (Adams et al., 2019). A traumatic event (TE) has been defined by Schneider, Palmer, Romero and O'Regan (2015, p.157) as "any accidental man-made disaster (e.g., Chernobyl nuclear power plant disaster), natural disaster (e.g., flood, tornado) or deliberate man-made disaster (e.g., war)." The number of TEs an individual has faced as well as the time since a TE are also important factors to consider (Falkenstein, C'DeBaca, Belon \& Castillo, 2017). While prior research has compared a military sample to a non-military/civilian sample (Blau \& Miller, 2019) or non-combat military veterans to combat military veterans (Galor \& Hentschel, 2013), to date there has been little research directly comparing trauma events, PTSD and coping styles between three distinct samples: civilian, non-combat military veteran, and combat military veteran. The goal of this study was to compare the three samples on these variables, with the research question asking if there were significant differences between these samples on TE-related variables.

\subsection{Describe Relevant Scholarship}

As defined by the American Psychiatric Association (2013), PTSD is a disorder that can develop after a person witnesses or experiences a traumatic event, such as combat, physical/sexual assault, extreme stress, or a natural disaster. PTSD can affect different populations, civilian, as well as military. For example, Chinawa, Chinawa, Aniwada, Amdai, Ndukuba and Uwaezuoke (2018) found PTSD was a concern for Nigerian medical students, while Pless Kaiser, Cook, Glick and Moye (2019) focused on the prevalence of PTSD in military veterans. Spouses of deployed military personnel can be susceptible to mental health issues/PTSD (Verdeli, Vousoura, Baily, Belser, Van De Wal, \& Manos, 2011). 
Coping styles can affect how an individual adjusts to a TE and PTSD. One general distinction between types of coping is approach versus avoidance (Boyraz, Waits, Felix, \& Wynes, 2016). In approach focused coping (Carver, 1997) one tries to deal directly with the stressor (e.g., planning, positive reframing, acceptance), which is more functional. However, with avoidance focused coping the person is trying to escape and evade feelings of distress (e.g., denial, venting, humor). This general type of coping is more dyyfunctional (Carver, 1997). Prior research (Bedard-Gilligan, Cronce, Lehavot, Blayney, \& Kaysen, 2014) has found avoidance coping styles and avoidance symptoms of PTSD to be related but distinct constructs. Shechory Bitton (2014) found a positive relationship between emotional or avoidance coping and PTSD. However, Schechory Bitton (2014) combined all specific avoidance coping scales (e.g., venting, denial) into one general measure. Longitudinal research (e.g., $\mathrm{An}, \mathrm{Fu}, \mathrm{Wu}$, Lin, \& Zhang, 2013) found the while individuals with higher PTSD symptoms can turn to avoidance coping mechanisms to alleviate their distress, such avoidance coping can result in more distress. An et al. (2013) also used a general avoidant coping measure. This study focused on tesing the specific relationships of three avoidance/dysfunctional scales, i.e., venting, denial, and humor, to PTSD, as well as variable differences between the study samples.

\subsection{State Hypotheses and Their Correspondence to Research Design}

Some prior studies have only used one sample in studying variables related to PTSD. For example Boyraz et al. (2016) used a general adult civilian sample, Shechory Bitton (2014) focused on a sample of ultra-Orthodox Jewish battered women in Israel, while Falkenstein et al. (2017), Maguen et al. (2019), and Tsai, El-Gabalawy, Sledge, Southwick and Pietrzak (2105) worked with US military veterans. Other studies have compared two samples. Schneider et al (2015) used archival data to test the impact of a residential rehabilitation treatment program (RRTP) on PTSD symptom severity improvement and quality of life for two military groups: a combat-related trauma group and non-combat related trauma group. They found that the RRTP reduced PTSD symptom severity and increased quality of life, regardless of trauma exposure group. Galor and Hentschel (2013) split Israeli combat and non-combat veterans into PTSD, depression, and control groups and found that the PTSD group was in the worst psychological state (e.g., highest emotional pain, lowest life satisfaction). The research design used in this study is unique, i.e., comparing three distinct samples - civilian, non-combat military veteran, and combat military veteran, on number of TEs, time since last TE, venting, denial, dark humor, and PTSD. Given the lack of prior research comparing these three distinct samples, the exploratory research question asked: are there differences on number of TEs, time since last TE, venting, denial, dark humor, and PTSD between civilian, versus non-combat military veteran versus combat military veteran samples?

\section{Method}

\subsection{Participants and Procedure}

In the Spring of 2019 a pre-tested Qualtrics survey link was sent out asking respondents if they had experienced a past traumatic event (TE), and if so to answer items related to how they experienced/dealt with this TE. Prior research has indicated there is generally minimal risk when asking respondents to recall a prior TE (Ferrier-Auerbach, Erbes, \& Polusny, 2009). In addition, respondents could skip an item if it was too upsetting to answer. Military veteran respondents, either with combat experience or not, came from several different sources. One source was the Mid-Atlantic US University student chapter Veterans' Association. A second source was different contacts the second author had as a military veteran with different US-based veteran-oriented organizations. These organization were primarily smaller non-profits organized to support veterans and their families. The civilian sample came from contacts both authors had with non-profit trauma-oriented groups. These trauma-oriented groups supported adults dealing with some type of family-related loss, e.g., due to illness, accident, overdose, or domestic violence, or some type of work-related death/injury, e.g., due to crime, fire, or an accident. The survey was anonymous and took approximately 15 minutes to fill out. Once respondents submitted this first survey, they were automatically taken to a separate second very brief survey. This survey asked for an email address so respondents could be randomly selected for either $\$ 50, \$ 20$, or $\$ 10$ multiple gift card drawings. The first item in the initial survey was a voluntary consent item, and respondents were instructed not to take the survey if they were under 18 years old. University Institutional Review Board approval was given for this project. Over a period of approximately three months, there were 320 respondents to the first survey, and 269 to the second survey. Unfortunately, $68(21 \%)$ of the respondents to the first survey had over $90 \%$ missing data and were discarded, leaving a sample of 252 respondents.

\subsection{Measures}

Civilian, versus non-combat military veteran versus combat military veteran. Respondents were asked, "which category best described them, where 1 = civilian (non-military); 2 = non-combat military veteran; and $3=$ 
combat-experienced military veteran. The sample sizes for each were: $1=$ civilian, $\mathrm{n}=99 ; 2=$ non-combat military veteran, $\mathrm{n}=61$; and $3=$ combat-experienced military veteran, $\mathrm{n}=92$.

Most powerful prior traumatic event (TE). A 14 item TE measure was used, asking respondents to pick "the one most powerful traumatic event you have faced either in the line of duty/doing your job, or in a non-work situation. This is the event that you feel had the greatest impact on you." The 14-items adapted some items from with previous TE measures (Boyraz et al., 2016; Pietrzak \& Cook, 2013), including items asking about death or serious injury due to work or non-work accident, natural disaster, illness, or domestic violence. However, given the focus on also comparing military combat versus non-combat veterans, several new TE items were items were included asking about specific military-related situations. In addition, a separate "other" category allowed the respondent to fill in their own most powerful TE if it was not on the list. This results of this measure, separated by civilian $(n=99)$ versus non-combat military vetean $(n=61)$ versus combat military veteran samples $(n=92)$, is reported in Table 1 of the Results section.

Traumatic event variables. Two items were measured. The first asked respondents "if you have experienced more than one trauma from the above list of 14 categories, please indicate how many trauma events you have experienced." The response scale was from $1=2$ to $6=$ more than 6 . Responses to this item were added to the initial "most powerful TE" answer to create a "total number of traumatic events" variable used in subsequent data analyses. The second item asked, "how long ago did you face the one most powerful traumatic event you identified above" (in the survey). Response categories ranged from $1=$ less than 6 months ago, to $14=$ over 50 years ago. Prior research has suggested greater accuracy with general categories versus a specific time, especially with a longer recall time period (Friedman, 1993).

Demographic variables. Five demographic variables were asked: gender, where $1=$ male, $2=$ female; race, where $1=$ African American, $2=$ American Indian, $3=$ Asian, $4=$ Hispanic, $5=$ Multi-racial, $6=$ Pacific Islander, $7=$ White; age, indicated in years; highest education level, where $1=$ high school diploma, to $6=$ doctorate, medical, dental or law degree; and occupational breakdown "if you are currently working either part-time (less than 35 hours/week) or full-time (at least 35 hours/week), what occupation best describes your current position?" These results are reported in Table 2 of the Results section.

Coping variables. Three variables were measured, venting, denial, and dark humor. As noted in the Introduction, prior research has focused more on general avoidance measures, versus specific avoidance scales. The frame of reference provided was "please answer these items thinking about the one most powerful traumatic event you experienced." Two two-item coping scales from Carver (1997) were used: venting and denial. A sample item for venting was "I have let my emotions really come out, e.g., yelling." A sample item for denial was "I have been saying to myself 'this isn't real'." Based on conversations with several military veterans while piloting the survey, the two humor items in Carver (1997) were modified to be more serious, e.g., "making 'fun' (e.g., finding dark humor) of the situation helps", and "being sarcastic helps me deal with it." This scale was re-labeled "dark humor." Items were answered on a 7-pont scale, where $1=$ strongly disagree to $7=$ strongly agree. Coefficient alphas for these scales in this study were: venting $=.74$; denial $=.75$; and dark humor $=.86$. These alphas compare favorably to those cited in Carver (1997), venting $=.50$; denial $=.54$; and humor $=.73$.

Post Traumatic Stress Disorder (PTSD). This variable was measured using the Severity of Posttraumatic Stress Symptoms-Adult nine-item scale (American Psychiatric Association, 2013). This scale was available for research use without permission. The referent was "how much have you been bothered during the past four weeks by each of the following problems that occurred or became worse after the one most power traumatic event you experienced." Boyraz et al. (2016) used a four week time frame for recall in their study. Items focused on PTSD symptoms including: having "flashbacks" that the traumatic event was happening again; feeling very upset when something reminded you of your traumatic event experience; feeling jumpy or easily startled by something, e.g., an unexpected noise; and being "super alert," on guard or constantly on the lookout for danger. Items were answered on a 5 -point scale, where $1=$ not at all to $5=$ extremely. The coefficient alpha for this scale was .92 . Boyraz et al. (2016) reported a coefficient alpha of .93.

\subsection{Data Analyses}

All data were analyzed using SPSS-PC version 24 (SPSS, 2015). Frequency breakdowns and percentages are reported for the most powerful TE and demographic variables, comparing the three samples. Means, standard deviations and correlations between continuous variables were calculated using the combined samples. There was minimal missing data. Demographic differences between samples were tested for. Analysis of variance (ANOVA) was used to test for initial differences between the three samples for six variables: number of TEs; time since last TE; venting; denial; dark humor and PTSD. If the overall F-test was significant, post hoc pair-wise comparisons 
between groups was made using the least squared difference test (Stevens, 1996). A significance level of $p<.10$ (two-tailed) was used as the cutoff for statistical significance. Hopkins, Marshall, Batterham and Hanin (2008, p.6) have argued that $\mathrm{p}=.10$, with a $90 \%$ confidence is "an appropriate default level of confidence."

\section{Results}

\subsection{Most Powerful TE and Demographic Variable Breakdown by Sample}

Results are broken down comparing civilian vesus non-combat military veteran versus combat military veteran samples. Looking at the most powerful TE (Table 1), the highest frequency specific TE frequency for civilan sample was "non-work: non-violent death (e.g., illness, accident, natural disaster) of a family member, close friend," $n=24(24 \%)$. For the non-combat veteran sample the highest frequency specific TE was "non-work: experiencing personal domestic violence/sexual assault/physical abuse," $n=10(17 \%)$. Finally, for the combat veteran sample it was was "seeing a fellow soldier killed/severely wounded," $\mathrm{n}=33(36 \%)$.

Table 2 shows the demographic breakdown for the three samples. Both military samples were male-dominated, while the civilian sample was female-dominated. Further testing using MedCalc's (2020) comparison of proportions showed significant gender differences between all samples. Both military samples had significantly higher percentages of males than the civilian sample: non-combat military sample versus civilian sample, Chi-square $=9.49, p<.01$, and combat military sample versus civilian sample, Chi-square $=37.41, p<.001$. In addition, there was a significant difference for gender between military samples, such that the combat sample had a higher percentage of males than the non-combat sample, Chi-square $=6.90, p<.01$.

All three samples were predominantly White. Age was reported in years but is collapsed into categories to save space in the Table. The age group 19-25, $\mathrm{n}=30(30 \%)$ was the highest frequency category for the civilian sample; $26-32, n=13(21 \%)$ was the highest frequency for the non-combat military sample; and $33-39, n=28$, (30\%) was the highest frequency category for the combat military sample. For all three samples, a four-year degree was the highest education level frequency category. There were no other significant demographic differences between the three samples. For current occupational category, education-related (e.g., teacher) was the highest for the civilian sample, $\mathrm{n}=16(16 \%)$; while being retired was the highest for both the non-combat military, $\mathrm{n}=12(20 \%)$ and combat military, $\mathrm{n}=20(20 \%)$.

Table 1. Most Powerful Traumatic Event by Civilian versus Non-combat Military Veteran versus Military Combat Veteran Samples

\begin{tabular}{llll}
\hline & $\begin{array}{l}\text { Civilian } \\
\text { Sample } \\
(\mathrm{n}=99)\end{array}$ & $\begin{array}{l}\text { Non-combat Military } \\
\text { Veteran Sample } \\
(\mathrm{n}=61)\end{array}$ & $\begin{array}{l}\text { Combat Military } \\
\text { Veteran Sample } \\
(\mathrm{n}=92)\end{array}$ \\
\hline $\begin{array}{l}\text { Killing/severely wounding enemy soldiers } \\
\text { Killing/severely wounding civilians }\end{array}$ & $\mathrm{n}=0$ & $\mathrm{n}=0$ & $\mathrm{n}=10(11 \%)$ \\
$\begin{array}{l}\text { Seeing a fellow soldier killed/severely wounded } \\
\text { Being severely wounded/injured in combat }\end{array}$ & $\mathrm{n}=1(1 \%)$ & $\mathrm{n}=0$ & $\mathrm{n}=5(2 \%)$ \\
$\begin{array}{l}\text { Killing/ wounding someone committing a crime } \\
\text { Seeing a work colleague killed/severely wounded }\end{array}$ & $\mathrm{n}=0$ & $\mathrm{n}=0$ & $\mathrm{n}=7(8 \%)$ \\
$\begin{array}{l}\text { Seeing a civilian(s) killed/severely injured during a crime } \\
\text { scene, fire or accident }\end{array}$ & $\mathrm{n}=1(1 \%)$ & $\mathrm{n}=0$ & $\mathrm{n}=0$ \\
$\begin{array}{l}\text { Suffering a serious personal work-related injury/accident } \\
\text { (being unable to work) }\end{array}$ & $\mathrm{n}=1(1 \%)$ & $\mathrm{n}=4(4 \%)$ \\
$\begin{array}{l}\text { Seeing a work colleague suffer a serious work-related } \\
\text { injury/accident (being unable to work) }\end{array}$ & $\mathrm{n}=2(2 \%)$ & $\mathrm{n}=2(3 \%)$ & $\mathrm{n}=6(7 \%)$ \\
$\begin{array}{l}\text { Non-work: violent death of a family member (e.g., spouse, } \\
\text { parent, child)/close friend, including suicide and drug } \\
\text { overdose }\end{array}$ & $\mathrm{n}=6(6 \%)$ & $\mathrm{n}=6(10) \%$ & $\mathrm{n}=1(1 \%)$ \\
$\begin{array}{l}\text { Non-work: non-violent death (e.g., illness, accident, natural } \\
\text { disaster) of a family member/close friend }\end{array}$ & $\mathrm{n}=24(24 \%)$ & $\mathrm{n}=7(12 \%)$ & $\mathrm{n}=0$ \\
\hline
\end{tabular}


Non-work: serious personal illness/injury/accident

$\mathrm{n}=11(11 \%) \quad \mathrm{n}=5(8 \%)$

$\mathrm{n}=4(4 \%)$

Non-work: experiencing personal domestic violence/sexual assault/physical abuse

$\mathrm{n}=15(15 \%) \quad \mathrm{n}=10(17 \%) \quad \mathrm{n}=0$

Non-work: witnessing domestic violence/sexual assault/physical abuse

$\mathrm{n}=3(3 \%) \quad \mathrm{n}=2(3 \%)$

$\mathrm{n}=1(1 \%)$

Table 2. Demographic Variables - Civilian versus Non-combat Military Veteran versus Military Combat Veteran Samples

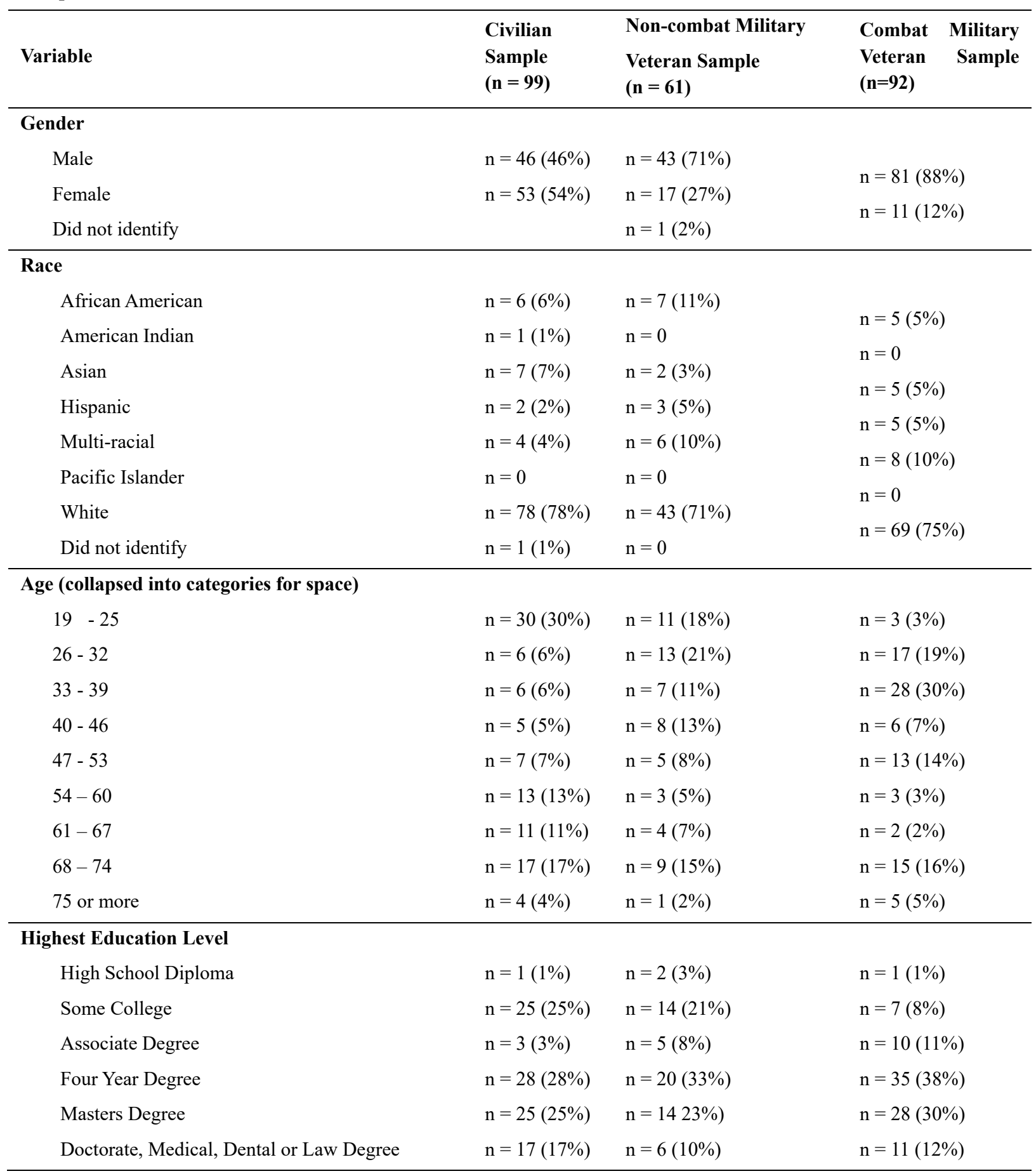




\section{Current Occupation - largest categories}

Police Officer

First Responder (e.g., Paramedic)

Physical Health-related (e.g., nurse)

Mental Health-related (e.g., therapist)

Education-related (e.g., teacher)

Financial Services (e.g., banking)

Government/Public Administration

Hospitality-related

Manufacturing-related

Construction-related (e.g., engineer)

Transportation-related

Entertainment (e.g., sports, media)

Other - (biggest listings)

Retired

Not working

Active duty military

Army/National Guard Reserves

Graduate Student

$\begin{array}{lll}\mathrm{n}=4(4 \%) & \mathrm{n}=3(5 \%) & \mathrm{n}=3(3 \%) \\ \mathrm{n}=3(3 \%) & \mathrm{n}=0 & \mathrm{n}=0 \\ \mathrm{n}=4(4 \%) & \mathrm{n}=2(3 \%) & \mathrm{n}=7(8 \%) \\ \mathrm{n}=9(9 \%) & \mathrm{n}=2(3 \%) & \mathrm{n}=4(4 \%) \\ \mathrm{n}=16(16 \%) & \mathrm{n}=11(18 \%) & \mathrm{n}=4(4 \%) \\ \mathrm{n}=4(4 \%) & \mathrm{n}=1(2 \%) & \mathrm{n}=1(1 \%) \\ \mathrm{n}=2(2 \%) & \mathrm{n}=2(3 \%) & \mathrm{n}=5(5 \%) \\ \mathrm{n}=5(5 \%) & \mathrm{n}=1(2 \%) & \mathrm{n}=5(5 \%) \\ \mathrm{n}=3(3 \%) & \mathrm{n}=0 & \mathrm{n}=3(3 \%) \\ \mathrm{n}=0 & \mathrm{n}=3(5 \%) & \mathrm{n}=0 \\ \mathrm{n}=2(2 \%) & \mathrm{n}=0 & \mathrm{n}=0 \\ \mathrm{n}=1(1 \%) & \mathrm{n}=2(3 \%) & \mathrm{n}=41(41 \%) \\ \mathrm{n}=24(24 \%) & \mathrm{n}=24(39 \%) & \mathrm{n}=20(20 \%) \\ \mathrm{n}=0 & \mathrm{n}=12(20 \%) & \mathrm{n}=14(14 \%) \\ \mathrm{n}=0 & \mathrm{n}=8(13 \%) & \mathrm{n}=4(4 \%) \\ \mathrm{n}=0 & \mathrm{n}=0 & \mathrm{n}=3(3 \%) \\ \mathrm{n}=5(5 \%) & \mathrm{n}=2(3 \%) & \mathrm{n}=0 \\ \mathrm{n}=4(4 \%) & \mathrm{n}=2(3 \%) & \end{array}$

\subsection{Means, Standard Deviations and Correlations for Continuous Variables for Combined Sample}

Table 3 shows the full sample means, standard deviations and correlations for continuous variables for the full sample. There are generally lower levels of the avoidance three coping styles, and they are sufficiently independent of each other to be used separately (Carver, 1997; Stevens, 1996). There is also a lower level of PTSD. Looking at correlations with PTSD, being younger, having more TEs, and higher venting, denial, and dark humor are each significantly related to PTSD.

\subsection{Test of Research Question}

Given the absence of prior research comparing civilan versus non-combat military veteran versus combat military veteran samples, a general comparison was made to assess are there differences on number of TEs, time since last TE, venting, denial, dark humor, and PTSD between these samples? The results are shown in Table 4. Finding a significant overall $\mathrm{F}$ test then allows for comparing groups. Using the $\mathrm{p}<.10$ threshold (Hopkins et al., 2008), a significant F-test value was found for Number of TEs $F(2,245)=9.94, p<.001$. Post hoc testing, using ${ }^{\text {superscripts }}$ for cells to indicate differences, showed that both military sample groups were higher than the civilian group. For the variable Time Since Last TE, the overall $F(2,245)=2.61, p<.10$. Post hoc testing showed that the combat military veteran sample was higher than the civilian and non-combat military veteran samples. There was no significant F-test value for PTSD, $F(2,245)=1.65, p<.20$. This non-significant value does not allow for subsequent post hoc testing between groups (Stevens, 1996), although the non-combat military sample had the highest PTSD. However, there were significant $\mathrm{F}$ values found for the three avoidance coping styles: venting, $F(2,245)=2.46, p<.10$; denial, $F(2,245)=3.03, p<.05$; and dark humor, $F(2,245)=2.32, p<.10$. The pattern of followup post hoc testing across these three main effects was consistent, finding that the non-combat veteran sample had the highest levels of venting $(M=3.53)$, denial $(M=3.58)$, and dark humor $(M=4.06)$. Post hoc tests revealed that the non-combat veteran sample used significantly more venting and denial than both the civilian and combat military veteran groups; and more dark humor than the civilian sample. 
Table 3. - Full Sample - Means, Standard Deviations, and Correlations for Continuous Variables

\begin{tabular}{|c|c|c|c|c|c|c|c|c|c|}
\hline Measure & M & SD & 1 & 2 & 3 & 4 & 5 & 6 & 7 \\
\hline 1. Age $^{\mathrm{a}}$ & 29.04 & 18.35 & $(---)$ & & & & & & \\
\hline 2. Total Number of Traumatic Events ${ }^{\mathrm{b}}$ & 2.80 & 1.92 & -.14 & $(----)$ & & & & & \\
\hline $\begin{array}{l}\text { 3. Time Since Most Powerful Traumatic } \\
\text { Event }^{c}\end{array}$ & 5.74 & 3.50 & $.55^{* *}$ & -.07 & $(---)$ & & & & \\
\hline 4. Venting ${ }^{\mathrm{d}}$ & 3.10 & 1.83 & $-.15^{*}$ & $.26^{* *}$ & .02 & $(----)$ & & & \\
\hline 5. Denial ${ }^{\mathrm{d}}$ & 3.23 & 1.85 & -.09 & $.15^{*}$ & $-.18 * *$ & $.52 * *$ & $(----)$ & & \\
\hline 6. Dark Humor ${ }^{d}$ & 3.69 & 2.04 & $-.37 * *$ & $.36^{* *}$ & $-.16^{*}$ & $.40 * *$ & $.15^{*}$ & $(----)$ & \\
\hline 7. Post Traumatic Stress Disorder ${ }^{\mathrm{d}}$ & 2.17 & 1.03 & $-.18 * *$ & $.35^{* *}$ & -.08 & $.60^{* *}$ & $.58 * *$ & $.35^{* *}$ & $(---)$ \\
\hline
\end{tabular}

$(\mathrm{n}=249) \mathrm{p}<.05 ; * * \mathrm{p}<.01$ (two-tailed).

${ }^{\text {a }}$ Age, measured in years

${ }^{\mathrm{b}}$ Total Number of Traumatic Events, $1=1$ to $7=$ more than 6

${ }^{\mathrm{c}}$ Time Since Most Powerful Traumatic Event, where $1=$ less than 6 months ago, $2=6$ months to 1 year, $3=1$ to 2 years, $4=3$ to 5 years, $5=6$ to 10 years, $6=11$ to 15 years, $7=16$ to 20 years, $8=21$ to 25 years, $9=26$ to 30 years, $10=31$ to 35 years, 11

$=36$ to 40 years $12=41$ to 45 years, $13=46$ to 50 years, $14=$ over 50 years

${ }^{\mathrm{d}}$ Venting, Denial, Dark Humor, Post Traumatic Stress Disorder, $1=$ strongly disagree to $7=$ strongly agree.

Table 4. Univariate Tests on Number of Traumatic Events (TEs), Time Since Last Traumatic Event, Three Types of Coping Styles and Post Traumatic Stress Disorder (PTSD) and Post Hoc Tests of Sample Cell Means

\begin{tabular}{|c|c|c|c|c|c|c|c|c|c|c|c|c|c|c|c|c|c|c|}
\hline \multirow{2}{*}{ Variables $^{\mathrm{a}}$} & Nun & nber of & TEs & Time $s$ & ince $\mathrm{La}$ & ast TE & & Venting & & & Denial & & Dar & $\mathrm{k}$ Hum & nor & & PTSD & \\
\hline & \multicolumn{3}{|c|}{$\mathrm{F}=9.94 * *$} & \multicolumn{3}{|c|}{$\mathrm{F}=2.61+$} & \multicolumn{3}{|c|}{$\mathrm{F}=2.45+$} & \multicolumn{3}{|c|}{$\mathrm{F}=3.03^{*}$} & \multicolumn{3}{|c|}{$\mathrm{F}=2.32+$} & \multicolumn{3}{|c|}{$F=1.65$} \\
\hline Cell Means & (1) & (2) & (3) & (1) & (2) & (3) & (1) & (2) & (3) & (1) & (2) & (3) & (1) & (2) & (3) & (1) & (2) & (3) \\
\hline (1) Civilian $(\mathrm{n}=97)$ & $2.17^{\mathrm{c}}$ & $2.79^{\mathrm{d}}$ & $3.37^{\mathrm{d}}$ & $5.45^{\mathrm{c}}$ & $5.26^{\mathrm{c}}$ & $6.41^{\mathrm{d}}$ & $2.89^{\mathrm{c}}$ & $3.53^{\mathrm{d}}$ & $3.02^{\mathrm{c}}$ & $3.33^{\mathrm{c}}$ & $3.58^{\mathrm{d}}$ & $2.87^{\mathrm{c}}$ & $3.36^{\mathrm{c}}$ & $4.06^{\mathrm{d}}$ & 3.75 & 2.03 & 2.31 & 2.22 \\
\hline \multicolumn{19}{|c|}{ (2) Non-combat Military } \\
\hline Veteran $(\mathrm{n}=61)$ & & & & & & & & & & & & & & & & & & \\
\hline
\end{tabular}

(3) Combat Military

Veteran $(\mathrm{n}=91)$

Note. $+\mathrm{p}<.10 ; * \mathrm{p}<.05 ; * * \mathrm{p}<.01$ (two-tailed).

${ }^{a}$ Variables - all items measured on 7-point response scale, $1=$ strongly disagree to $7=$ strongly agree.

${ }^{\mathrm{b}}$ Within each outcome, cell means that do not share the same superscript ${ }^{\mathrm{c} \text { versus d }}$ are significantly different at the 0.05 level by the Least Squared Difference post hoc test.

\section{Discussion}

There was partial support for the original research question of finding variable differences between the three samples. The strongest result was finding that the three avoidance coping styles of venting, denial and dark humor were highest for the non-combat military veteran group. Although there was no significant difference between these three groups on PTSD, prior correlation analyses in this study showed significant positive correlations between each of these three avoidance coping styles to PTSD. The positive correlations of these three avoidance coping styles to PTSD were consistent with prior research (Bedard-Gilligan et al., 2014).

Overall, these combined results highlight the importance of not just focusing on combat military verteran samples (Adams et al., 2019) or civilan samples (Boyraz et al., 2016) when studying the effects of trauma. When studying military veteran samples, a combat versus non-combat distinction should be made. Military non-combat veterans should not be neglected. The results of this study suggest that military non-combat veterans may need some type of intervention to help them focus on using more approach oriented coping styles, e.g., positive reframing (Blau \& Miller, 2019), acceptance or planning (An et al., 2013; Boyraz et al., 2016) to deal more constructively with PTSD. 
Trauma-focused therapies are available for treating PTSD. Schneider et al. (2015) found that a residential rehabilitation treatment program reduced PTSD symptom severity and increased quality of life, regardless of trauma exposure when comparing military combat versus non-combat groups. Bichescu, Neuner, Schauer, and Elbert (2007) found older adults randomly assigned to Narrative Exposure Therapy for PTSD benefitted more than those assigned to psychoeducation treatment.

It is important to help all types of military veterans to successfully transition to civilian life (Weiss et al., 2019). Veterans' support groups can first help non-combat military veterans to acknowledge their trauma in a safe and confidential environment. After such acknowledgement, work can begin to reframe such trauma into some type of learning experience that can promote positive growth for those affected. Such recognition can be witnessed through story telling within well defined safe spaces with empathetic community witnesses. Combat and non-combat veterans may be reluctant to tell their stories in the presence of community members. However, prior research has shown that social support can help post traumatic growth (Tsai, El-Gabalawy, Sledge, Southwick, \& Pietrzk, 2015), and there is growing anecdotal evidence that such growth is encouraged when military veterans and civilians can discuss traumatic episodes together.

\subsection{Study Limitations}

As with all studies, this research has several limitations. One is the threat to internal validity, i.e., other explanations for the results found (Stevens, 1996). Several prominent factors which jeopardize internal validity include: history; maturation; subject selection bias; and instrumentation (Stevens, 1996). As an example of history, this study found that the greater number of TEs an individual reported the higher their PTSD. However, the time since the most powerful TE the person faced varied across the samples, and how one dealt with this most powerful TE could have changed over time. Dealing with a TE over time could also be related to maturation in terms of age. Correlation results showed that as respondents aged their avoidance coping styles and PTSD decreased. Pless Kaiser et al. (2019) found lower rates of PTSD in older versus younger adults. Looking at subject selection bias, respondents self-selected into taking the survey, based on prior experience with some type of TE. The authors approached different organizational sources, e.g., University student chapter Veterans' association; grief-focused groups, but had no control over which respondents decided to take the survey. In addition, the economic incentive of multiple cash gift card drawings "backfired" and we believe contributed to $21 \%$ of the sample only filling out a few survey items (over $90 \%$ missing data) to then become eligible for the gift drawing. The data from these respondents had to be discarded. In addition, this self-selection resulted in significant gender differences between samples, with the combat military veteran sample having the highest percentage of males, followed by the non-combat military veteran sample, followed by the civilian sample. Instrumentation is important to acknowledge. Only three avoidance coping styles were tested, venting, denial and dark humor. The relationships of other avoidance coping styles (e.g., substance abuse, self-blame), as well as approach coping styles (e.g., reframing, acceptance, emotional support) to PTSD needs to be compared across these three samples in future research. People may use a combination of both avoidance and approach coping styles in dealing with trauma-related variables. In addition, since all measures were self-reported, method bias is a concern. However, the one-factor test results showed that when using all items in a principal compents analysis (PCA), seven factors had an eigenvalue of over 1 and the first factor accounted for $29 \%$ of the variance. If this first factor represents method bias, it is not a major limitation (Podsakoff, MacKenzie, Lee \& Podsakoff, 2003). Collecting all the data at once in this study does not allow for causal inferences to be made.

\subsection{Conclusion}

The research design of this study is unique in comparing three distinct samples, civilian, non-combat military veteran and combat military veteran on trauma-related variables. Future study is needed on additional three-sample comparisons to test the generalizability of these findings. The results showed that the non-combat military veterans had higher avoidance coping, i.e., venting, denial, and dark humor, than the other two samples. All three avoidance coing styles were significantly positively related to PTSD. PTSD can be a trigger for suicide (Department of Veterans Affairs, 2019). We believe these findings draw attention to the importance of distinguishing combat versus non-combat military veterans, so that non-combat military veterans can get resources/support in dealing with prior traumatic events they have faced. It is important to help all veterans find positive approach-oriented coping strategies to support their transition to civilian life. Greater usage of approach-oriented coping should help to reduce PTSD and by doing so then lower the earlier-cited distressing US military veteran suicide rate of 16.8 per day (Department of Veterans Affairs, 2019).

\section{Acknowledgments}

The first author gratefully acknowledges the sabbatical support of Temple University in the preparation of this 
paper. The second author acknowledges the support of veteran and non-profit organizations to collect data and support research into why veterans and military personnel commit suicide at an alarming rate.

\section{References}

Adams, R. E., Urosevich, T. G., Hoffman, S. N., Kirchner, H. L., Figley, C. R., Withey, C. A., ... \& Boscarino, J. A. (2019). Social and psychological risk and protective factors for veteran well-being: The role of veteran identity and its implications for intervention. Military Behavioral Health, 7(3), 304-314. https://doi.org/10.1080/21635781.2019.1580642

American Psychiatric Association. (2013). Diagnostic and statistical manual of mental disorders (5th ed., text rev.). Washington, DC: American Psychiatric Association. https://doi.org/10.1176/appi.books.9780890425596

An, Y., Fu, F., Wu, X., Lin, C., \& Zhang, Y. (2013). Longitudinal relationships between neuroticism, avoidance coping, and posttraumatic stress disorder symptoms in adolescents following the 2008 Wenchuan Earthquake in China. Journal of Loss \& Trauma, 18, 556-571. https://doi.org/10.1080/15325024.2012.719351

Bedard-Gilligan, M., Cronce, J. M., Lehavot, K., Blayney, J. A., \& Kaysen, D. (2014). The relationship between assault and physical health complaints in a sample of female drinkers: Roles of avoidance coping and alcohol use. Journal of Interpersonal Violence, 29, 1359-1379. https://doi.org/10.1177/0886260513507139

Bichescu, D., Neuner, F., Schauer, M., \& Elbert, T. (2007). Narrative exposure therapy for political imprisonment related chronic posttraumatic stress disorder and depression. Behaviour Research and Therapy, 45(9), 2212-2220. https://doi.org/10.1016/j.brat.2006.12.006

Blau, G., \& Miller, G. (2019). Comparing correlates of posttraumatic growth for military veteran versus non-military veteran samples. Journal of Behavioral Health, 8(4), 143-151. https://doi.org/10.5455/jbh.20190627063836

Boyraz, G., Waits, J. B., Felix, V., \& Wynes, D. D. (2016). Posttraumatic stress and physical health among adults: The role of coping mechanisms. Journal of Loss and Trauma, 21(1), 47-61. https://doi.org/10.1080/15325024.2014.965978

Carver, C. S. (1997). You want to measure coping but your protocol's too long: Consider the Brief COPE. International Journal of Behavioral Medicine, 41(1), 92-100. https://doi.org/10.1207/s15327558ijbm0401_6

Chinawa, A. T., Chinawa, J. M., Aniwda, E., Amadi, O., Ndukuba, A. C., \& Uwaezuoke, S. N. (2018). Spectrum of anxiety disorders among medical students in a Nigerian medical school: A cross-sectional study with standardized screening tools. Journal of Educational and Developmental Psychology, 8(2), 132-146. https://doi.org/10.5539/jedp.v8n2p132

Department of Veterans Affairs. (2019). National veteran suicide prevention annual report. U.S. Department of Veterans Affairs. Retrieved from https://www.mentalhealth.va.gov/docs/data-sheets/2019/2019_National_Veteran_Suicide_Prevention_Annu al_Report_508.pdf

Falkenstein, M. J., C'deBaca, J., Belon, K., \& Castillo, D. C. (2017). Predictors of PTSD improvement with cognitive/exposure group interventions in operation Enduring Freedom/Operation Iraqi Freedom female veterans. Journal of Loss and Trauma, 22(4), 297-306. https://doi.org/10.1080/15325024.2017.1284514

Friedman, W. J. (1993). Memory for the time of past events. Psychological Bulletin, 113(1), 44-66. https://doi.org/10.1037/0033-2909.113.1.44

Ferrier-Auberach, A. G., Erbes, C. R., \& Polusny, M. A. (2009). Does trauma survey research cause more distress than other types of survey research? Journal of Traumatic Stress, 22(4), 320-323. https://doi.org/10.1002/jts.20416

Galor, S., \& Hentschel, U. (2013). PTSD and depression among combat and noncombat Israeli veterans. Military Behavioral Health, 1, 159-166. https://doi.org/10.1080/21635781.2013.839323

Hopkins, W. G., Marshall, S. W., Batterham, A. M., \& Hanin, J. (2008). Progressive statistics for studies in sports medicine and exercise science. Medicine \& Science in Sports \& Exercise, 40, 1-10. https://doi.org/10.1249/MSS.0b013e31818cb278

Maguen, S., Li, Y., Madden, E., Seal, K. H., Neylan, T. C., Patterson, O. V., .. \& Shiner, B. (2019). Factors associated with completing evidence-based psychotherapy for PTSD among veterans in a national healthcare 
system. Psychiatry Research, 274, 112-128. https://doi.org/10.1016/j.psychres.2019.02.027

MedCalc. (2020). Comparison of proportions. Retrieved December 16, 2020, from https://www.medcalc.org/calc/comparison_of_proportions.php

Pietrzak, R. H., \& Cook, J. M. (2013). Psychological resilience in older U.S. veterans: Results from the National Health and Resilience in Veterans Study. Depression \& Anxiety, 30, 432-43. https://doi.org/10.1002/da.22083

Pless Kaiser, A. P., Cook, J. M., Glick, D. M., \& Moye, J. (2019). Posttraumatic stress disorder in older adults: A conceptual review. Clinical Gerontologist, 42(4), 359-376. https://doi.org/10.1080/07317115.2018.1539801

Podsakoff, P., Mackenzie, S., Lee, J., \& Podsakoff, N. (2003). Common method biases in behavioral research: Critical review of the literature and recommended remedies. Journal of Applied Psychology, 88(5), 879-903. https://doi.org/10.1037/0021-9010.88.5.879

Schneider, B. P., Palmer, G. A., Romero, R., \& O'Regan, J. (2015). Post-traumatic stress disorder and quality-of-life outcomes of veterans seeking treatment in a residential rehabilitation treatment program. Military Behavioral Health, 3, 157-166. https://doi.org/10.1080/21635781.2015.1009215

Shechory Bitton, M. (2014). PTSD, posttraumatic growth, and coping among Ultra-Orthodox Jewish battered women in Israel. Journal of Loss and Trauma, 19(2), 155-172. https://doi.org/10.1080/15325024.2012.760383

SPSS-PC, version 24. (2015). Statistical package for the social sciences. Chicago: IBM Corp.

Stevens, J. (1996). Applied multivariate statistics for the social sciences (2nd ed.). Mahwah, NJ: Lawrence Erlbaum.

Tsai, J., El-Gabalawy, R., Sledge, W. H.., Southwick, S. M., \& Pietrzak, R. H. (2015). Posttraumatic growth among veterans in the USA: Results from the National Health and Resilience in Veterans Study. Psychological Medicine, 45, 165-179. https://doi.org/10.1017/S0033291714001202

Verdeli, H., Vousoura, E., Baily, C., Belser, A., Van De Wal, E., \& Manos, G. (2011). Adaptation and testing of interpersonal psychotherapy for military spouses. Journal of Educational and Developmental Psychology, 1(1),118-126. https://doi.org/10.5539/jedp.v1n1p118

Weiss, E. L., Rubin, A., \& Graeser, M. (2019). Transitioning to civilian life scale (TCLS): Development, reliability, and validity. Military Behavioral Health, 7(1), 57-63. https://doi.org/10.1080/21635781.2018.1540317

\section{Copyrights}

Copyright for this article is retained by the author(s), with first publication rights granted to the journal.

This is an open-access article distributed under the terms and conditions of the Creative Commons Attribution license (http://creativecommons.org/licenses/by/4.0/). 